\title{
Seroprevalence of piroplasmosis with tick distribution in northern Iraq
}

\author{
L.T. Omer ${ }^{1}$, M.A. Kadir ${ }^{2}$ and J.S. Ahmed ${ }^{3}$ \\ ${ }^{1}$ College of Veterinary Medicine, Dohuk University, ${ }^{2}$ College of Medicine, Kirkuk University, Iraq \\ ${ }^{3}$ Research Center Borstel, Germany
}

\begin{abstract}
The current study was carried out on blood samples of 299 local breed female cattle in Erbil, Duhok and Suleimania, Northern Iraq, for the period from beginning of January till end of December 2006 for detection of piroplasmosis. By direct blood smear examination, the rate of Theileria annulata alone was $45.1 \%$ while in mixed infections with Babesia was $11.7 \%$. The total rate of Theileria infection was $56.9 \%$. The haematological parameters of cattle infected with Theileria alone were $\mathrm{PCV}=27 \%, \mathrm{RBC}=5.6 \mathrm{million} / \mathrm{cm}^{3}$ and $\mathrm{Hb} 9.5 \mathrm{~g} /$ liter did not vary from non infected ones. While in mixed infections (Theileria +Babesia) the blood picture values were decreased dramatically and were $\mathrm{PCV}=18 \%, \mathrm{RBC}=4.08$ million $/ \mathrm{cm}^{3}$ and $\mathrm{Hb} 5.7 \mathrm{~g} / \mathrm{l}$. Using enzyme linked immunosorbent assay technique (ELISA), the seropositivity of Theileria was $77.9 \%$, while Babesia was $12.4 \%$. The overall rate of seropositivity by ELISA was $90.3 \%$ for piroplasms while by blood smears examination the rate of infected animals was $56.9 \%$. From 5804 ticks collected from animal body, the constituencies of the ticks were $81.7 \% \mathrm{H}$. anatolicum anatolicum, 15.3\% H. marginatum marginatum, 2.82\% Rhipecephalus appendiculatus and 10 ticks $(0.2 \%)$ were not identified. The highest rate of ticks was found attached to udder and under tail (77\%), followed by ears $(20 \%)$ and hind limbs and around eyes (3\%). The distribution of ticks was highest in spring $96.0 \%$, followed by summer $4.0 \%$. No ticks were detected in winter and autumn. The greatest number of ticks was in March (37.9\%) followed by May (32.23\%), April (25.85\%), June (2.17\%), July (1.68\%) and August (0.17\%).
\end{abstract}

Keywords: Piroplasmosis; ticks; Iraq Available online at http://www.vetmedmosul.org/ijvs

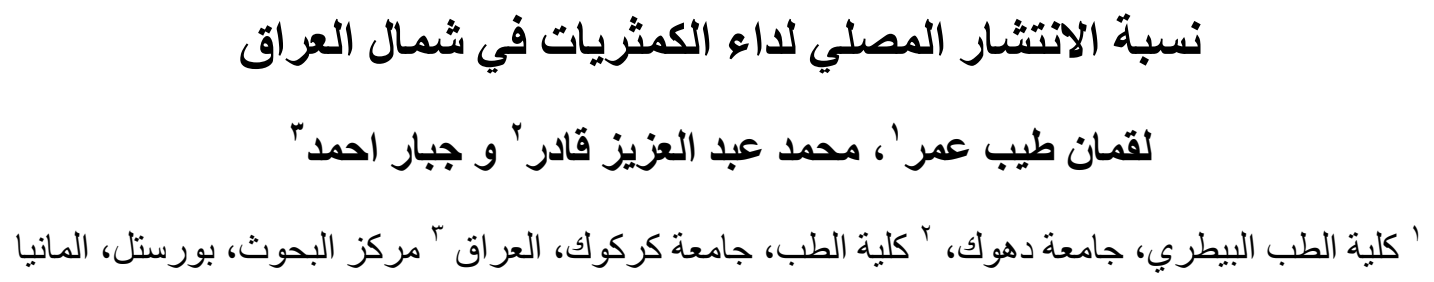

الخلاصة

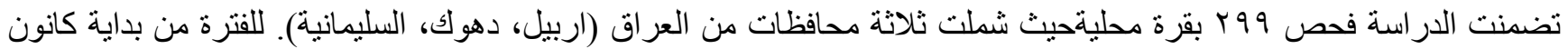

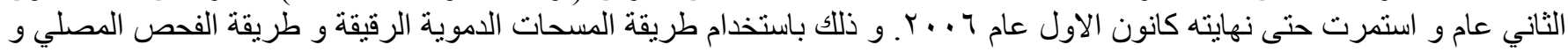

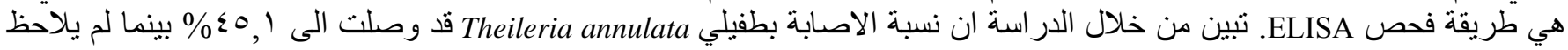

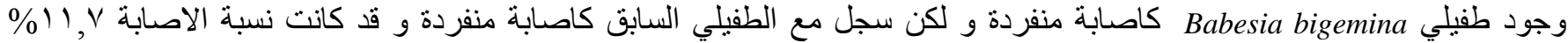

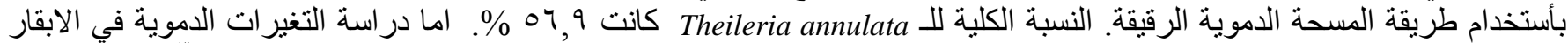

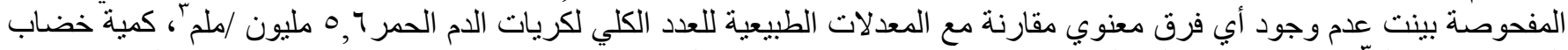

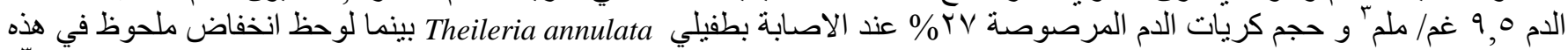

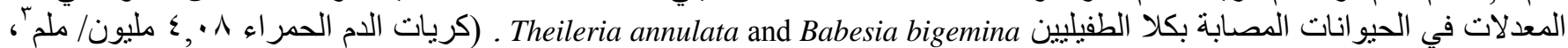

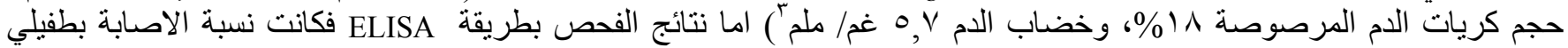

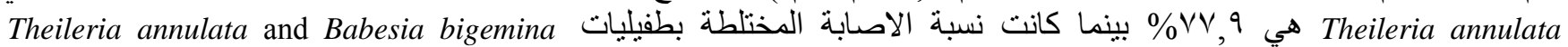

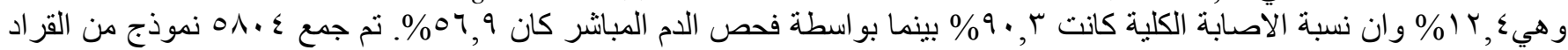

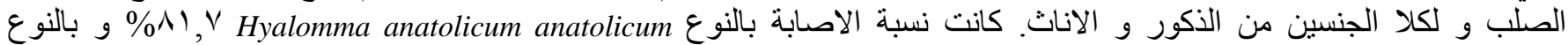
كانت r rolomma marginatum marginatum 


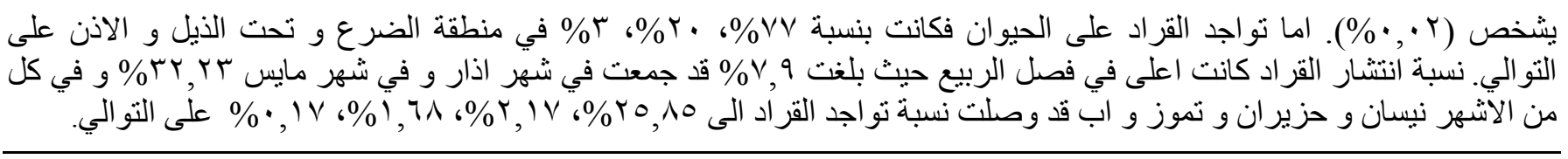

\section{Introduction}

Piroplasmosis, caused by Theileria or Babesia, is one of the most common complexe diseases in tropical and subtropical regions since it affects wide range of ruminants and causes sever economical losses (1). Bovine piroplasmosis is caused by Theileria annulata and Babesia bigemina is common problem in the north of Iraq. However, little is known about the epidemiology of piroplasmosis in this region.

Hassan (2) collected blood samples from 250 cattle (50 tick-infested, 50 tick non-infested and 150 farm cattle) during the period from June 2007 to August 2008 to detect Mediterranean theileriosis in Sulaimania region. He found the highest frequency in tick infested cattle $54 \%$, followed by farm cattle $21.3 \%$ and the lowest in tick non-infested cattle $6 \%$, by Giemsa stained blood smear examination.

Generally, the diagnosis of clinical infection by piroplasmosis in cattle is usually based on clinical signs, history of disease and vector distribution and identification of the piroplasm and schizont stages in blood and lymph node smears. Carrier animals, in which low numbers of erythrocytes remain infected, are important contributors to the transmission of the infection by tick bites. Hence, detection of piroplasms in carrier animals is very important to control the infection. However, detection of piroplasms is not easy and it is generally not possible to discriminate pathogenic and non-pathogenic species that may occur simultaneously within the same host $(3,4)$.

There are several techniques for serodiagnosis of piroplasmosis such as agglutination test, Immunofluorescent antibody test (IFAT) and enzymelinked immunosorbent assay (ELISA). Principally they are easy to perform and proved to be powerful diagnostic and research tools (5).

ELISA has been successfully adapted for the detection of antibodies to piroplasmosis and has been shown to detect antibodies for a longer period time than the indirect fluorescent antibody test (6). It is easy to perform, inexpensive, accessible to be standardized and would fulfill the requirement for epidemiological surveys when compared to the IFAT (7).

The present study was planned to show the prevalence of Babesia and Theileria spp. And the distribution of tick vector in Duhok, Erbil and Suleimania governorates, Northern Iraq.

\section{Materials and methods}

The study was conducted during the period from beginning of January to end of December 2006 at different localities in Duhok, Erbil and Suleimania provinces of the Northern Iraq. The investigated area extended from the latitude $33 \mathrm{~N}$ to the latitude $38 \mathrm{~N}$ and longitude $42 \mathrm{E}$ to longitude $46 \mathrm{E}$. This area is distinguished by Mediterranean mountains climate in the winter and desert dry climate in summer.

The survey study was carried out on randomly selected local breed, outdoor grazing apparently healthy female cattle's. The study involved 299 cattle, 100 from each Dohuk and Suleimania governorate and 99 cattle from Erbil governorate. Age of the cattle was above one year old.

Blood samples were collected from jugular vein, divided into two portions. One portion was put in plain vacationer tube, centrifuged and sera were stored at $-20 \mathrm{C}$, while the second portion of blood put in the heparinized vacationer was used for estimation of $\mathrm{PCV}, \mathrm{RBC}$ and $\mathrm{Hb}$ in addition to that blood smears were prepared from each sample and stained with Giemsa stain (8).

Enzyme-linked immunosorbent assay (ELISA) for Theileria annulata was carried on using Theileria annulata surface protein "TaSP" following the protocol described by Bakheit, et al., (9). Enzyme-linked immunosorbent assay for B. bigemina was conducted using ELISA kit (Svanova, Sweden) according to the instruction in the manual.

Total body collection of ticks was made from cattle using a pair of blunt forceps. Ticks were identified according to Walker et al. (10). The identification was confirmed by Iraqi National Museum -Baghdad.

Statistical analysis was conducted using SPSS. ChiSquare analysis was used to show significant difference between groups at level 5\% (11).

\section{Results}

In Giemsa-stained blood smears, from total of 299 cattle, $135(45.1 \%)$ were positive for Theileria, 35 (11.7\%) were positive for mixed infections of Theileria and Babesia. No positive cases were found for Babesia alone.

The distribution of Theileria was similar in Duhok and Suleimania, where 44 animals (44\%), while 47/99 (47.4\%) was found in Erbil. Regarding the mixed infection the following results were reported: $12.1 \%$ in Erbil, $13 \%$ in Duhok and 10\% in Suleimania.

The haematological parameters did not vary significantly between normal and Theileria infected animals, 
while declined substantially in mixed infections of Theileria and Babesia (Table 1).

Theileria annulata specific antibodies were detected in sera of 233 animals out of 299 (77.9\%), when these samples were tested using ELISA based on a recombinant protein from Babesia bigemina, a total of 37 animals (12.4\%) were positive, which were also positive for $T h$. annulata (Table 2).

A comparison between the efficiency of ELISA and microscopical examination clearly showed that ELISA was significantly more efficient for detection of positive cases than direct microscopic examination. Hence, ELISA allowed a better detection (90.3\%) of infected animals, while microscopically examination detected only $56.9 \%$ of the cases (Table 3 ).

A total of 5804 ticks (4350 males and 1454 females) was collected and characterized according to the key for identification of Ixodidae. It was found that $4740(81.7 \%)$ were Hyalomma anatolicum anatolicum and 890 (15.3\%) Hyalomma marginatum marginatum while Rhipicephalus appendiculatus constituted only 164(2.8\%) and 10 ticks were not identified (Table 4).

Table 1: The PCV, RBC count and Hb values of infected and non-infected cattle.

\begin{tabular}{lcccc}
\hline Parameters & Normal* & Theileria annulata & $\begin{array}{c}\text { Mixed infection } \\
\text { Theileria+Babesia }\end{array}$ & Non-infected \\
\hline $\mathrm{PCV} \%$ & $6-42 \%$ & $27 \pm 0.022$ & $18 \pm 0.034$ & $30 \pm 0.046$ \\
$\mathrm{RBC} 10^{6} / \mathrm{ml}$ & $5-8 \times 10^{6}$ & $5.6 \pm 0.25$ & $4.09 \pm 0.64$ & $5.6 \pm 0.53$ \\
$\mathrm{Hb}$ $/ 1$ & $8-14$ & $9.5 \pm 0.66$ & $5.7 \pm 0.635$ & $10.6 \pm 1.13$ \\
\hline
\end{tabular}

* Coles (12) $\mathrm{P}<0.05$.

Table 2: Sero-prevalence of T. annulata and B. bigemina infection from 299 samples.

\begin{tabular}{lcccc}
\hline Infection & $\begin{array}{c}\text { Theileria annulata } \\
\text { alone }\end{array}$ & $\begin{array}{c}\text { Babesia } \\
\text { Bigemina }\end{array}$ & $\begin{array}{c}\text { Babesia and Theileria } \\
\text { Mixed infection }\end{array}$ & Total \\
\hline No. Positive & 233 & 0 & 37 & 270 \\
Positive \% & 77.9 & 0 & 124 & 90.3 \\
\hline
\end{tabular}

Table 3: Comparison between ELISA and blood smears for the diagnosis of Theileria and Babesia infections.

\begin{tabular}{lcccc}
\hline Infections & \multicolumn{2}{c}{ Blood smear } & \multicolumn{3}{c}{ ELISA test } \\
\cline { 2 - 5 } & Number & $\%$ & Number & \% \\
\hline Theileria annulata & 135 & 45.1 & 233 & 77.9 \\
Mixed infected & 35 & 11.7 & 37 & 12.4 \\
Total positive & 170 & 56.9 & 270 & 90.3 \\
Total negative & 129 & 43.1 & 29 & 9.6 \\
\hline
\end{tabular}

Table (4) Distribution of ticks according to species.

\begin{tabular}{lcccc}
\hline \multirow{2}{*}{ Tick species } & \multicolumn{2}{c}{ Hyalomma spp. } & \multirow{2}{*}{ R. appendiculatus } & \multirow{2}{*}{ Unknown } \\
\cline { 2 - 3 } & anatolicum & marginatum & & 164 \\
Number & 4740 & 890 & $2.8 \%$ & 10 \\
Percentage (\%) & $81.7 \%$ & $15.3 \%$ & $0.2 \%$ \\
\hline
\end{tabular}

It was found that $4468(77 \%)$ ticks were attached to the udder and to under tail, whereas $1161(20 \%)$ were attached to the ears and $175(3 \%)$ on the hind limbs and around the eyes. No ticks were seen on the chest of the examined cows (Table 5).

The distribution of ticks in the region was highest in spring $(96.0 \%)$ followed by summer $(4.0 \%)$. No ticks were detected in winter and autumn. The higher number of ticks could be detected in March 2200 (37.9\%), followed by May 1870 (32.23\%), April 1500 (25.85\%), June 126 (2.17\%), July $98(1.68 \%)$ and August 10 (0.17\%).
Table (5). Tick distribution on different parts of the animal body.

\begin{tabular}{lcc}
\hline Locations & Tick number & Percentage \\
\hline Udder and under tail & 4468 & 77 \\
Ears & 1161 & 20 \\
Hind limb & 125 & 2 \\
Around eyes & 50 & 1 \\
\hline Total & 5804 & 100 \\
\hline
\end{tabular}




\section{Discussion}

In the present study $56.9 \%$ of cattle were found infected with Theileria annulata and $11.7 \%$ of them were associated with Babesia infection by microscopic examination of Giemsa stained blood smears. While 91\% of cattle had antibodies against Theileria and mixed infections of Theileria and Babesia using TaSP recombinant ELISA (9). The lower rate of infections in direct blood smears examination reflects the low sensitivity of microscopic examination of blood smears for detection of Theileria and both Theileria and Babesia infections (13).

The PCV, $\mathrm{RBC}$ count and $\mathrm{Hb}$ values of negative animals and Theileria infected animals were almost identical. These values were substantially reduced in animals infected with both Theileria and Babesia. This may be due to Babesia amplified the pathogenesis of the mixed infection.

The results revealed that $91 \%$ of the tested cattle produced antibodies against the TaSP recombinant protein indicating that these animals experienced an infection with Th. annulata. Moreover, these data indicated that the region from where the samples were collected can be considered as an endemic region regarding tropical theileriosis.

Regarding the suitability of TaSP-ELISA used in this study, investigation was performed to validate this test under field conditions. Salih et al. (14) tested more than 800 serum samples and found that TaSP-based ELISA had higher sensitivity than a number of other ELISA tests based on the use of Tams-1 recombinant protein or crude Theileria material. Taken together these data, TaSP was a useful serological tool for epidemiological studies.

Assessment of antibodies against B. bigemina, was conducted using ELISA kit (Svanova ${ }^{\circledR}$, Sweden). In $12.4 \%$ of the tested animals, mixed infections with Theileria and Babesia were found. These study of Camus and Montenegro-James (15), observed in a previous study that the incidence of babesiosis ranged between $18 \%$ and $71 \%$, as detected by ELISA. The difference in the rate of infection may be related to location and environmental variation in two studies.

Finding of both Hyalomma antolicum antolicum and Hyalomma marginatum marginatum were also reported by earlier studies in Iraq (16). The highest rate of ticks were attached to udder and under tail followed by ears. In Sulaimaniyah province (17) found Hyalomma anatolicum anatolicum, $H$. marginatum, Rhipicephalus turanicus and $R$. sanguineus in sheep.

It is concluded that theileriosis is more widely distributed than babesiosis in northern Iraq. ELISA method was more sensitive than microscopical examination of Giemsa-stained smears. The distribution of Hyalomma ticks was greater than Rhipicephalus. Both tick species were predominant in spring and early summer.

\section{References}

1. Bock R, Jackson L, DeVos A, Jorgensen W. Babesiosis of cattle. Parasitology 2004; 129(suppl. 1): S247-S269.

2. Hassan AH. A pathological study on theileriosis in cattle in Sulaimaniyah region, Iraq. Ph.D. Thesis College of Vet Medicine, Sulaimania Univ., 2010.

3. Papadopoulos B, Brossard M, Perie NM. Piroplasms of domestic animals in Macedonia region of Greece. 2. Piroplasms of cattle. Veterinary Parasitology, 1996; 63: 57-66.

4. Garcia-Sanmartin J, Nagore D, Garcia-Perez AL, Juste RA, Hurtado A. Molecular diagnosis of Theileria and Babesia species infecting cattle in Northern Spain using reverse line blot macroarrays. BMC Vetrinary Research, 2006; 2: 16-22.

5. Pipan E, Morzaria S, Spooner P. Theileriosis. In OIE Manual of diagnostic tests and vaccines for terrestrial animals 2008; Vol.2 $6^{\text {th }}$ edition, PP. 789-804.

6. Kachani M, Flach EJ, Williamson S, Ouhelli H, El-Hasaoui M, Spooner RLThe use of an enzyme-linked immunosorbent assnay for tropical theileriosis research in Morocco. Preventive Vet Med 1996; 26: $329-340$

7. Seitzer U, Bakheit MA, Salih DA, Ali A, Haller D, Yin H, Schnittger L, Ahmed JS. From molecule to diagnostic tool: Theileria annulata surface protein TaSP. Parasitology Research 2007; 101(Supplement 2): S217-S223

8. Dacie and Lewis (2006). Practical Haematology 10 th Ed. Churchill Livingston, Elsevier. 2006; 736p

9. Bakheit MA, Schnittger L, Salih DA, Boguslawski K, Beyer D, Fadl $\mathrm{M}$, Ahmed JS. Application of recombinate Theileria annulata surface protein in an indirect ELISA for the diagnosis of tropical theileriosis. Parasitol. Res 2004; 92(4): 299-302.

10. Walker A, Bouattour A, Camicas L, Estrado-Pena A, Horak IG, Latif AA, Pergram RG, Preston PM. Ticks of domestic animals in Africa. A Guide to Identification of Species. Bioscience Reports, 42 Comiston Drive, Edinburgh EH105QR, Scotland, U.K. 2003.

11. Preacher KJ. Calculation for the chi-square test: An interactive calculation tool for Chi-square tests for goodness of fit and independence (Computer software), 2001. Available from http://www.quantpsy.org.

12. Coles EH. Veterinary Clinical Pathology. $4^{\text {th }}$. Ed. WB.Saunders Co. Phiadelphia, London, 1986. pp:10-72

13. Ziam H. Benaouf $\mathrm{H}$. Prevalence of blood parasites in cattle from Wilayates of Annaba and El-taref east Algeria. Arch Inst Pasteur Tunis 2004; 81(1-4): 27-30.

14. Salih.E, Ahmed JS, Bakheit MA, Ali EB, El Hussein AM, Hassan SM, Shariff OE, Fadl M, Jongejan F. Validation of the indirect TaSP enzyme-linked immunosorbent assay for diagnosis of Theileria annulata infection in cattle. Parasito Res 2005; 97: 302-308.

15. Camus E, Montenegro-James S. Bovine anaplasmosis and babesiosis in the lesser Antilles: risk assessment of an unstable epidemiologic situation. Vet Res 1994; 25(2-3): 313-317.

16. Hawa NJ, Jasim FA, Abdul-Aziz MO. A Survey for the species of tick and its geographical distribution in Iraq to specify the species for transmission of haemorrhagic fever. Iraqi J.Agri., (special issue) 2000; 5(4): 87-97.

17. Mustafa BHS. Study on some epidemiological factors of hard tick (Ixodidae) in sheep in sulaimania province with trial to immunize rabbits against larval extracts of Hyalomma anatolicum anatolicum. Ph.D. Thesis, Sulaimania Univ. 2011. 